\title{
Agindo sobre a diferença: atividades de empoderamento feminino em prol da permanência de mulheres em cursos de Tecnologia da Informação
}

\author{
Natália C. Louzada ${ }^{1}$, Thalia S. Santana ${ }^{1}$, Ianka T. B. Assis ${ }^{1}$, Ramayane B. Braga ${ }^{1}$, \\ Adriano H. Braga ${ }^{1}$ \\ ${ }^{1}$ Instituto Federal Goiano - Campus Ceres (IF GOIANO) \\ Caixa Postal 51 - 76.300-000 - Ceres - GO - Brasil \\ \{thaliassantana15, iankatalitaa\}@gmail.com, \\ \{ramayane.santos, natalia.louzada, adriano.braga\}@ifgoiano.edu.br
}

\begin{abstract}
In its emergence, an expressive social communication of female participation, gave a social and professional contribution to the activities of mathematical education and secretariat. However, as the fields of informatics and technology gained greater value, the female position in the areas declined progressively. This extoporcionalities are being refined to stigmas of gender and the struating the contribution of businesswoman with computed, desestimulating and desmerdentement the actions in the reports ramos. In this sense, we propose to present the initiatives of training and capacity building in the scope of an extension project with the computer courses, middle and higher level, with the objective of combating female school dropout.
\end{abstract}

Resumo. Em seu surgimento, a computação envolveu expressiva participação feminina, dada a inserção social e profissional de mulheres em atividades ligadas à educação matemática e ao secretariado. Entretanto, à medida em que os campos de informática e tecnologia adquiriram maior valorização, a presença feminina nestas áreas diminuiu progressivamente. Esta desproporcionalidade vem sendo atribuída a estigmas de gênero e ao apagamento da contribuição de mulheres à computação, desestimulando e desmerecendo sua atuação nos referidos ramos. Nesse sentido, nos propomos a apresentar iniciativas de empoderamento e capacitação no âmbito de um projeto de extensão junto a cursos de informática, de nível médio técnico e superior, com o objetivo de combater a evasão escolar feminina.

\section{Introdução}

O primeiro curso brasileiro da área de computação, criado em 1971, no Instituto de Matemática e Estatística (IME) da Universidade de São Paulo (USP), recebeu em sua primeira turma 20 estudantes, dentre eles 14 do sexo feminino. Já em 2016, segundo publicação recente do portal Jornal da USP intitulada "Por que as mulheres 'desapareceram' dos cursos de computação?", dos 41 ingressantes do curso de Bacharelado em Ciências da Computação (IME) apenas 15\% eram mulheres.

Antes da criação do personal computer, entre fins da década de 1960 e início dos anos 1970, os computadores eram grandes máquinas mainframes de calcular e processar dados, utilizadas especialmente por agências de governo e grandes empresas. As atividades 
realizadas por estas máquinas estavam associadas à função de secretariado que, por sua vez, era socialmente tratada como um "trabalho feminino".

Com efeito, entre os primeiros cursos de graduação em Ciências da Computação no Brasil era comum haver um grande número de estudantes mulheres, muitas vezes matriculadas em cursos de Licenciatura em Matemática e posteriormente transferidas à computação. Entretanto, a partir dos anos 1980, contexto em que se popularizou o computador pessoal criado pela International Business Machines (IBM) e quando houve progressiva valorização de carreiras e salários nas áreas de informática e tecnologia, uma grande inversão nas relações de gênero destes campos profissionais transcorreu em todo o mundo (SANTOS, 2018).

Os motivos da atual desproporcionalidade entre homens e mulheres com atuação em ciência e tecnologia vêm sendo relacionada à questões de ordem sociocultural. Afinal, é pouco compreensível que as estudantes do sexo feminino tenham deixado de optar por estas carreiras justamente quando as mesmas estavam em franca expansão. Estudos como o relatório "O ABC da Igualdade de Gênero na Educação", elaborado em 2015 pela Organização para a Cooperação e Desenvolvimento Econômico (OCDE) a partir da realização do Programa Internacional de Avaliação de Alunos (PISA) em mais de 60 países, nos dão pistas acerca das restrições encontradas por mulheres no âmbito das ciências exatas e atividades profissionais correlatas.

De acordo com o relatório, embora as meninas possuam melhor desempenho escolar geral, por outro lado, tendem a "ter baixo desempenho em comparação com os meninos quando são convidadas a pensar como cientistas, a exemplo de quando são convidadas a formular situações matematicamente ou interpretar fenômenos cientificamente" (PISA EM FOCO, 2015, s/p). Ainda conforme o documento, a falta de confiança atribuída ao "pensar cientificamente" causa franco impacto ao desempenho feminino, uma vez que o resultado entre as estudantes melhora conforme aumenta o sentimento de confiança em relação à disciplinas como a matemática (PISA EM FOCO, 2015, s/p).

Assim sendo, não é de se espantar que o relatório da OCDE tenha identificado que apenas 5\% das mulheres, entre 15 e 30 anos, residentes nos países membros da organização, optem por carreiras profissionais ligadas às áreas de ciências exatas, tais como engenharia ou computação. Em nossa interpretação, o referido problema está diretamente relacionado à constatações feitas pela OCDE acerca da relação entre as estudantes e seus pais, que tendem a perceber a atuação profissional em ciências exatas como " masculinas".

Os pais são mais propensos a esperar que os seus filhos, em vez de suas filhas, trabalhem em um campo da ciência, tecnologia, engenharia ou matemática - mesmo quando seus meninos e meninas de 15 anos de idade apresentam o mesmo nível de desempenho em matemática (PISA EM FOCO, 2015, s/p).

Assim, ainda que exista presença feminina em computação e tecnologia, o senso comum vem atribuindo a muitas destas carreiras a representação de "atividades masculinas", criando estigmas de gênero e impondo desvalorização ao trabalho feminino nestes campos (RAPKIEWICZ, 1998). No contexto brasileiro, essa circunstância encontra reflexos também nos níveis mais altos de formação acadêmica e produção de conhecimento, como foi demonstrado pelos dados do CNPq do ano de 2016, segundo os quais mais de $80 \%$ dos 
mestres e doutores em computação no país são homens (ALMEIDA; ZANLORENSSI, 2018).

É possível dizer, contudo, que a desproporcionalidade de gênero em profissões ligadas às ciências exatas acomete todo o Ocidente. A exemplo disso, no ano de 2017 a Microsoft realizou um estudo com 11.500 mulheres de 12 países europeus, na faixa etária de 11 a 30 anos, cujo relatório denominado "Why don't European girls like science or technology?" constatou que: a) a falta de profissionais do sexo feminino nas áreas de ciência, tecnologia, engenharia e matemática foi uma das principais razões pelas quais as mulheres entrevistadas não optaram por estas carreiras; b) mulheres jovens consideram não ter suficiente experiência prática em sua formação com os temas relacionados às referidas áreas, o que causa desestímulo; c) apenas $42 \%$ das entrevistadas vislumbram a possibilidade de optar por profissões ligadas à ciência, tecnologia, engenharia ou matemática; d) $60 \%$ das entrevistadas afirmou que se sentiria mais confiante em seguir tais profissões se homens e mulheres estivessem igualmente empregados nestas áreas.

Deste modo, podemos argumentar que as diferenças de gênero em atividades profissionais relativas à ciência e tecnologia não se relacionam a "aptidões naturais" distintas, mas ao resultado de construções sociais por meio das quais foram impostas restrições simbólicas às mulheres no âmbito do imaginário social. Na interpretação de Tabak (2002), foi justamente por meio da construção de uma imagem da ciência como masculina, e da elaboração de um estigma de gênero a partir do qual as mulheres foram tidas como inseguras e dotadas de competências inferiores, que se consolidaram barreiras explícitas ao acesso de mulheres às carreiras de caráter científico.

Com efeito, assim como acontece na grande área de ciências, dentro da subárea da ciência da computação também há apagamento e exclusão feminina, ocasionando transformações históricas no campo da tecnologia, que de maneira quase determinante torna-se uma "escolha" majoritariamente masculina. Assim, provocando a naturalização das relações sociais de gênero em áreas profissionais de informática e tecnologia (LETA, 2003; SCHWARTZ et al., 2006).

Na concepção do sociólogo Pierre Bourdieu (2002), a dominação masculina no Ocidente é resultado de uma violência simbólica exercida por meio da comunicação e do conhecimento que, ao ser reproduzida socialmente na dimensão do habitus, é naturalizada e imposta à sociedade como representação da realidade. Por este motivo, mesmo dotados de condições de poder muito distintas, homens e mulheres compartilham igualmente de tais representações violentas, cuja perpetuação se fundamenta em mecanismos criados por instituições históricas, como o Estado e a escola, responsáveis tanto pela elaboração dos princípios de dominação quanto por sua transferência ao espaço doméstico.

Nesse sentido, para o autor, caberia à história das mulheres desnaturalizar representações sexistas que, em verdade, são elaborações de natureza histórica (social, política, econômica, cultural). Isso porque recontar a trajetória feminina a partir do questionamento às tradições que nos parecem familiares contribuiria para transformar as atuais relações de força (material e simbólica) entre os sexos.

Cabe destacar que, segundo Schiebinger (2001, p.37), apenas no ano de 1913 a participação de mulheres na ciência se tornou objeto de estudo, sendo que, no Brasil, grandes investigações a esse respeito foram realizadas apenas a partir de 1998. Para ele, "a ciência moderna é um produto de centenas de anos de exclusão das mulheres". Por isso, "o processo 
de trazer mulheres para a ciência exigiu, e vai continuar a exigir, profundas mudanças estruturais na cultura, métodos e conteúdo da ciência"

No que se refere à computação, mesmo com o recente esforço de valorização das mulheres pioneiras na história da informática ainda não é evidente que o espaço social em tal campo possa ser ocupado por ambos os gêneros; uma vez que a contribuição feminina nesta área vem sendo omitida desde o século XVII, quando Augusta Ada Byron, Condessa de Lovelace, participou da invenção da primeira máquina de calcular algoritmos, sendo em seguida "esquecida pela história" até quase três séculos depois (SCHWARTZ et al., 2001).

Como já sabemos, a obliteração das figuras femininas e sua contribuição para o desenvolvimento científico deixa as mulheres do presente sem referências nas quais se inspirar, desestimulando sua identificação pessoal com as carreiras científicas. Nesse sentido, as novas narrativas acerca da participação feminina na história da ciência e da computação compõem hoje um campo social específico: constituído por relações e disputas entre seus diferentes agentes, para a conservação ou transformação da hierarquia de poder a que integram (BOURDIEU, 1988).

De maneira que, dentro de um cenário como este, faz-se necessário motivar meninas e mulheres por meio de ações que deem visibilidade aos importantes papéis ocupados por mulheres cientistas ao longo da história. Deste modo, o projeto Meninas Digitais no Cerrado vai de encontro a tais premissas, desconstruindo concepções preconceituosas por meio de debates críticos e, ao mesmo tempo, oferecendo oportunidades de capacitação técnica que estimulem a inserção feminina nas áreas profissionais de ciência e tecnologia.

\section{Contexto, metodologia e desenvolvimento do projeto}

A iniciativa de extensão sobre a qual se debruça o presente texto foi motivada pela preocupação quanto à violência de gênero (LINS et al., 2016) que perpassa os estereótipos sexistas vigentes no campo da informática, e seus possíveis impactos sobre a autoestima e o desempenho escolar das estudantes da área de informática. Assim, mediante o objetivo de combater a evasão feminina em cursos de informática e estimular o ingresso feminino em carreiras profissionais ligadas à computação, uma equipe interdisciplinar integrada por professoras de informática e história, bem como por estudantes de nível médio e superior na área de informática, foi formada para o desenvolvimento de atividades de extensão.

Posteriormente, a ação se desdobrou em um projeto de pesquisa, liderado por um professor de informática, por meio do qual pudemos verificar uma diminuição do ingresso de meninas na instituição, frente ao aumento das taxas de evasão e retenção escolar. E essa constatação nos ajuda a descrever o contexto no âmbito do qual, ao início do projeto, optamos por ações não apenas de capacitação (voltadas para a familiarização prática com softwares, hardwares e programação), como também atividades de empoderamento e reforço à auto-estima.

A noção de empoderamento é entendida por nós não apenas de maneira instrumental, a partir da qual busca-se "alcançar o poder" conquistando espaço nas estruturas econômicas e políticas da sociedade. Compreendemos empoderamento, sobretudo, como condição de expressão da liberdade de sujeitos e grupos para o exercício de suas capacidades, bem como para o acesso a recursos que lhes permitam transformar as relações sociais (políticas, culturais ou econômicas) em que estão inseridos (ONU, 1995). 
Sob a perspectiva de Foucault $(1995 ; 2004 ; 2009)$, a noção de poder deve ser pensada como conjunto de relações de forças historicamente situadas. Para ele, mediante o estabelecimento de determinados discursos como verdade, o poder operacionaliza suas relações, impondo normas que determinam as formas de viver - classificar, julgar, subjetivar e que sujeitam outros saberes e discursos dissonantes. Por isso, uma determinada economia do discurso é constantemente realimentada pela relação saber-poder, em que o discurso autorizado, dominante, reforça sempre sua condição de verdade.

Nesse sentido, o empoderamento feminino foi pensado no âmbito do projeto como um contra-discurso, cujas representações do feminino desnaturalizam os estereótipos normalizados acerca das aptidões e capacidades intelectuais das mulheres. E partindo desta perspectiva, adotamos 5 categorias de atividades no âmbito das quais foram desenvolvidas diversas ações, com caráter tanto prático quanto subjetivo:

- Capacitação tecnológica: Oferta de oficinas que trabalham conceitos como robótica e Arduíno, consideradas temáticas de interesse por meninas de cursos técnicos e graduação, trabalhando componentes como hardware e software; visitas técnicas para contato e aproximação de perfis profissionais femininos de êxito;

- Construção humana: Realizar rodas de conversa, mesas redondas, mostra de filmes abrangendo temas como relações sociais de gênero, equidade e sororidade; oficinas de confecção de cartazes sobre o papel e ótica da representação feminina; questionamentos voluntários acerca de estereótipos de gênero;

- Divulgação científica: Oferecer palestras e oficinas na instituição dos autores, bem como de modo itinerante em demais instituições e eventos, com enfoque na difusão de mulheres na ciência incluindo a abordagem acerca da presença feminina histórica na tecnologia, desde as primeiras gerações de computadores; produção de resumos e artigos com resultados de ações deste, além de estímulo a estudantes da instituição a criarem projetos com robótica e programação (por exemplo) em feiras de ciências e tecnologia;

- Representação e ampliação de alcance: Participar em mostras, feiras e exposições públicas divulgando o projeto; mantenimento de mídia social e elaboração de conteúdo para publicação como exemplos de mulheres na informática, curiosidades históricas e popularização de conceitos técnicos; criação de página eletrônica do projeto por participantes do mesmo, por meio de orientação e capacitação técnica promovida;

- Promoção de eventos: Organizar eventos valorizando a perspectiva feminina, a exemplo da iniciativa internacional Ada Lovelace Day (FINDING ADA, 2019) para incentivo e permanência de mulheres em STEM (Ciência, Tecnologia, Engenharia e Matemática); campeonatos de jogos em prol da desconstrução de estigmas de atividades ditas como "femininas" e "masculinas"; recepção e acolhimento de discentes calouras para aproximação, exposição de perspectivas e apresentação como coletivo de apoio. 
Entre os anos de 2016 e 2019, cerca de 40 atividades foram desenvolvidas, entre elas atividades organizadas por nós e outras nas quais participamos como convidadas. O projeto possui como público-alvo estudantes de nível médio técnico e graduação na área de computação. Todavia, discentes de demais cursos da instituição que sedia a iniciativa (Instituto Federal de Educação, Ciência e Tecnologia Goiano - Campus Ceres) se inseriram nas ações de maneira espontânea, a exemplo das estudantes dos cursos técnicos em agropecuária, meio ambiente e licenciatura em ciências biológicas, o que em nossa interpretação demonstrou a carência e necessidade de representatividade nesses outros contextos estudantis e profissionais.

O volume de trabalho, portanto, foi bastante significativo, o que foi suscitado pelo engajamento de estudantes e servidoras de diferentes áreas, tanto técnicas-administrativas quanto docentes da instituição, seja na realização das atividades previstas, seja na proposição de novas ações que, por fim, transcenderam positivamente os objetivos iniciais do projeto. De início, tais objetivos estavam centrados conforme apresentado na Tabela 1:

Tabela 1. Objetivos específicos propostos conforme o projeto de extensão.

\begin{tabular}{|l|l|}
\hline Capacitação & $\begin{array}{l}\text { Estimular o empreendedorismo e a criatividade no âmbito da atuação } \\
\text { profissional em computação; }\end{array}$ \\
\hline Representação & $\begin{array}{l}\text { Promover o contato entre estudantes e mulheres de sucesso na área de } \\
\text { informática através da participação em eventos acadêmicos; }\end{array}$ \\
\hline $\begin{array}{l}\text { Divulgação / } \\
\text { Representação }\end{array}$ & $\begin{array}{l}\text { Divulgar a computação e estimular a inclusão digital do público feminino } \\
\text { externo por meio da publicização dos produtos do projeto (vídeos, artes } \\
\text { visuais, cartilhas informativas destinadas às estudantes das áreas } \\
\text { eventos (acadêmicos ou não) tendo em vista a divulgação de nossos } \\
\text { cursos de Tecnologia da Informação; }\end{array}$ \\
\hline $\begin{array}{l}\text { Construção } \\
\text { humana / } \\
\text { Promoção de } \\
\text { eventos }\end{array}$ & $\begin{array}{l}\text { Organizar e executar a aplicação de oficina itinerante relatando a história } \\
\text { das mulheres na tecnologia. }\end{array}$ \\
\hline
\end{tabular}

Fonte: Própria (2019).

Todavia, as atividades de "formação humana" ganharam bastante espaço entre nossas ações, justamente pela ampla reverberação que o projeto encontrou ao desenvolver iniciativas de caráter interdisciplinar. Nesse sentido, a formação humana acabou permeando todas as demais categorias de atividades, uma vez que nossas realizações foram tomadas como momentos de valorização feminina para além da informática.

Uma destas atividades que ganhou notoriedade no projeto dado a seu elevado alcance foi a realização do Ada Lovelace Day. As atividades relacionadas à data foram pioneiras no sentido terem sido elaboradas por estudantes, para estudantes, com o objetivo de reconstruir o imaginário estudantil acerca de invenções e feitos de importância histórica, por meio de uma abordagem para além da computação. 
Na primeira edição do evento, em 2017, foram promovidas rodas de conversa sobre a presença feminina em ciência e tecnologia, com profissionais de ramos como Ciências Agrárias, Química, Informática, Filosofia e Educação que, além de discutir sobre as relações sociais de gênero, abordaram vivências pessoais de violência de gênero no âmbito de sua trajetória profissional. Também foram organizadas como ponto de partida para o debate com o público "mini-palestras" proferidas por estudantes, agrupadas em três temáticas norteadoras: a) Mulheres na Informática, b) Cotidiano feminino e c) Problemas das relações de gênero. Por fim, houve ainda o convite à escolas públicas de nível fundamental da região para uma conversa acerca do que é "coisa de menina" e "coisa de menino", a fim de desconstruir representações sexistas relativas à ciência e à tecnologia.

Em outro momento, já na edição de 2018, o evento destaque, de abertura das atividades, trouxe mulheres de diversas áreas da instituição para tratar de sua atuação e contribuições ao cotidiano técnico, burocrático e acadêmico. O objetivo foi oportunizar a visibilização dessas mulheres, possibilitando o re(conhecimento) dos estudantes a cargos e setores (como laboratórios de pesquisa e gerências financeiras), com as mais diferentes funções, em que há participação profissional feminina.

É importante destacar que a temática nos foi proposta por meio de consulta prévia feita à comunidade escolar, em que pedimos a descrição dos temas de interesse pessoal a serem abordados pelas atividades do Ada Lovelace Day. Nos pareceu muito significativo identificar tanto o desconhecimento acerca da atuação profisssional de mulheres na instituição, quanto o interesse por essa informação. Nesse mesmo sentido, a expressiva presença de professoras e servidoras entre o público do evento de abertura e nos demais debates promovidos ao longo Ada Lovelace Day foi vista por nós como evidência de um desejo de valorização, reconhecimento e respeito às mulheres e ao seu trabalho.

Para além de discussões realizadas na instituição de origem, outra das atividades de grande expressividade no projeto foi a oficina itinerante, oferecida em instituições e eventos relacionados à tecnologia para a apresentação de uma história das mulheres na computação.

Costumeiramente, tais fatos históricos relacionados à informática são apenas aludidos na delimitação de gerações de computadores, que foram marcos em cada estágio de evolução da tecnologia. Em contraponto, o projeto se propôs a realizar um levantamento do estado da arte da produção científica acerca da história das mulheres pioneiras da computação, a fim de elaborar uma narrativa histórica que não apenas insere tais mulheres e suas contribuições para as gerações de computadores, mas que (re)conta a história da computação sob a perspectiva da participação feminina. Objetivando, deste modo, retomar a relevância das figuras femininas na concepção da computação, a fim de estabelecer referências femininas que permitam a identificação de jovens mulheres com exemplos de sucesso, e suscitar discussões acerca dos motivos para o seu apagamento histórico.

Relatos de estudantes após as oficinas e palestras proferidas demonstraram espanto e curiosidade, principalmente em relação ao elevado quantitativo de mulheres na criação e permanente reconstrução da informática. Afirmações acerca do desconhecimento sobre o fato de uma mulher ser a primeira pessoa programadora da história (Ada Lovelace), por exemplo, demonstram o quanto tais informações eram inesperadas. Ao mesmo tempo, algumas discentes mencionaram sentir-se mais próximas da área a partir da visualização de perfis femininos. Colocando em cheque estigmas frequentemente reforçados, tais como: "mulher não sabe programar" e "programador é apenas um 'nerd' de óculos". 
A oficina itinerante, portanto, se mostrou um importante instrumento de empoderamento, tendo despertado interesse de participação entre homens e mulheres nos eventos que organizamos, nos minicursos que oferecemos em eventos externos, e nas palestras para que fomos convidados. Além disso, a iniciativa de divulgação da contribuição feminina na história da computação, ciência e tecnologia nos perfis do projeto em redes sociais, foi alimentada justamente pela pesquisa que viabilizou a referida oficina, tendo igualmente conquistado bastante adesão.

Em relação às avaliações das ações desenvolvidas, alguns dados corroboram a repercussão positiva do projeto. Em 2017, foi enviado aos participantes do Ada Lovelace Day um formulário de avaliação da programação, impacto e relevância do evento organizado. Além de questões como curso, turma e sexo, foram feitas outras cinco perguntas: "O que achou do evento?"; "Participaria novamente?"; "Qual a relevância?"; "O quanto gosta da área de TI?";"De um modo geral, gostou das atividades?" e "Sugestões".

No total, 33 pessoas se dispuseram a responder o formulário, sendo 78,9\% do sexo feminino e apenas $21,1 \%$ masculino. Nesta avaliação, $100 \%$ dos participantes consideraram o evento excelente, o que demonstra o interesse dos presentes pela temática, além do êxito na execução da proposta. Quanto ao questionamento sobre a relevância da atividade, aproximadamente $6,1 \%$ dos avaliadores julgaram como "importante" e os outros 93,9\% afirmaram ser "muito importante". Por fim, em 100\% dos questionários foi obtida a resposta de que participariam novamente do evento e que gostaram das atividades promovidas, incentivando a realização de uma nova edição em 2018.

A partir do questionamento relativo ao curso e função exercida na instituição, pudemos concluir que a maioria dos participantes era constituída por estudantes de informática $(51,5 \%)$, seguida de alunos dos demais cursos técnicos $(21,3 \%)$, docentes e servidores $(15,1 \%)$, e estudantes de cursos de graduação (3\%).

Em outra ação, referente ao Dia da Mulher no ano de 2018, que abordou a condição humana bem como direitos e conquistas femininas, 42 estudantes participaram. Dentre os que responderam à avaliação, cerca de 64,3\% disseram "se identificar bastante" com a temática apresentada, e outros $28,6 \%$ "se identificaram". Não houve apontamentos negativos e, novamente, $100 \%$ dos avaliadores afirmaram gostar da palestra promovida.

Por último, a mais recente ação de 2019 tratou-se de uma visita técnica a um evento de tecnologia, em alusão ao Dia da Mulher, com palestrantes femininas em apresentação de conteúdos técnicos. Embora 45 pessoas tenham participado, apenas 26 discentes se dispuseram a responder o formulário de avaliação enviado posteriormente ao evento. Do total, $88,5 \%$ deram nota máxima à organização da visita, e $100 \%$ se interessaram em participar de demais ações. Alguns inclusive fizeram menções sugestivas para participar de mais eventos organizados por mulheres, rodas de conversa sobre feminismo e também, acerca da representatividade de negros e comunidade LGBTQ+.

\section{Considerações finais}

Assim sendo, as atividades desenvolvidas pelo projeto de extensão Meninas Digitais no Cerrado têm se caracterizado pela alta frequência, formato curto, e abrangência local, tendo em vista a predominância de estudantes da própria instituição. A despeito de uma abrangência relativamente restrita, o projeto vem conseguindo acompanhar ano a ano as 
estudantes da instituição sede, o que nos permitirá em breve avaliar o sucesso quantitativo da iniciativa no combate à evasão escolar feminina no ensino médio técnico integrado e no curso superior de bacharelado em Sistemas de Informação.

A equipe conseguiu promover ainda boa circulação de seus extensionistas e produtos (oficinas itinerantes, cartilhas) em eventos de caráter tanto acadêmico quanto social, bem como realizou diversas atividades em cooperação com escolas públicas de nível fundamental, o que possibilitou o aumento de seu impacto sobre a comunidade externa.

As dificuldades encontradas estiveram relacionadas à baixa produção científica acerca da história das mulheres na computação produzida em língua portuguesa, o que se colocou como barreira às extensionistas na elaboração da oficina itinerante e do material destinado à disciplina de Fundamentos da Informática.

Além disso, o menor engajamento das estudantes de nível superior e a dificuldade de obter respostas aos questionários avaliativos têm sido outros dos obstáculos, dada a diferença entre os turnos das aulas para os níveis médio e superior na instituição, bem como o caráter voluntário e colaborativo das avaliações de atividades.

Consideramos ser importante destacar, sobretudo, o caráter interdisciplinar que o projeto adquiriu à medida em que foi tomado por mulheres - docentes, servidoras e estudantes de diferentes cursos da instituição - como uma iniciativa necessária, capaz de contribuir para a o empoderamento e inserção profissional feminina para além da informática. Participamos da elaboração de uma política anti-assédio institucional e, de certa forma, nos tornamos uma das referências no cotidiano escolar, tanto para as discussões sobre relações de gênero, quanto para iniciativas de acolhimento à mulheres.

Em algumas de nossas atividades de construção humana situações de violência de gênero (física e simbólica) foram denunciadas, assim como situações de vulnerabilidade foram manifestadas. Nesse sentido, a dimensão da sororidade (LAGARDE, 2006) foi ganhando espaço no projeto à medida em que, num contexto de crescimento da violência contra a mulher no Brasil (IPEA, 2018), nossas ações foram significadas pelas participantes como oportunidades de diálogo e informação. E à medida que nós vislumbramos na formação de redes de mulheres uma estratégia importante para o empoderamento e êxito escolar, não apenas nas áreas de informática ou ciências exatas.

\section{Referências Bibliográficas}

Almeida, R.; Zanlorenssi, G. (2018). Qual o gênero e a idade de mestres e doutores no Brasil, https://www.nexojornal.com.br/grafico/2018/05/23/Qual-o-g\%C3\%AAnero-e-a-idade-demestres-e-doutores-no-Brasil, Março.

Bourdieu, P. (1988). A gênese dos conceitos de habitus e de campo. O poder simbólico, 5, 59-73.

Bourdieu, P. (2002). A dominação masculina. Bertrand Brasil, 2a edição.

Finding Ada (2019). Ada Lovelace Day - Celebrating women in STEM. https://findingada.com/, Março.

Foucault, M. (1995). O sujeito e o poder. In: RABINOV, Paul; DREYFUS, Hubert. Michel Foucault, uma trajetória filosófica: para além do estruturalismo e da hermenêutica. Rio de Janeiro, Forense Universitária. 
Foucault, M. (2004). Microfísica do poder. Rio de Janeiro: Edições Graal, $20^{\mathrm{a}}$ edição.

Foucault, M. (2009). A ordem do discurso. São Paulo: Edições Loyola, $18^{\mathrm{a}}$ edição.

IPEA (2018). Atlas da Violência, http://www.ipea.gov.br/portal/images/stories /PDFs/relatorio_institucional/180604 atlas_da_violencia_2018.pdf, Março.

Lagarde, M. (2006). Pacto entre mujeres: sororidad. Aportes (25): 123-135.

Leta, J. (2003). As mulheres na ciência brasileira: crescimento, contrastes e um perfil de sucesso. Estudos avançados, 17(49), 271-284.

Lins, B. A., Machado, B. F., \& Escoura, M. (2016). Diferentes, não desiguais: a questão de gênero na escola. Editora Reviravolta.

OECD (2015). The ABC of Gender Equality in Education: Aptitude, Behaviour, Confidence. Pisa OECD Publishing, http://dx.doi.org/10.1787/9789264229945-en, Março.

ONU (1995). Declaração e Plataforma de Ação da IV Conferência Mundial Sobre a Mulher, http://onumulheres.org.br/wp-content/uploads/2014/02/declaracao_pequim.pdf, Março.

Pisa em Foco (2015). O que está por trás da desigualdade de gênero na educação?, http://www.oecd.org/pisa/pisaproducts/pisainfocus/PIF-49\%20(por).pdf, Março.

Rapkiewicz, C. E. (1998). Informática: domínio masculino?. Cadernos Pagu, (10), 169-200.

Santos, C. M. (2018). Por que as mulheres 'desapareceram' dos cursos de computação?, https://jornal.usp.br/universidade/por-que-as-mulheres-desapareceram-dos-cursos-de-com putacao/, Março.

Schiebinger, L. (2001). O feminismo mudou a ciência. Bauru: Edusc, 32.

Schwartz, J. et al. (2006). Mulheres na informática: quais foram as pioneiras?. Cadernos Pagu, (27), 255-278.

Tabak, F. (2002). O laboratório de Pandora: estudos sobre a ciência no feminino. Editora Garamond.

Trotman, A. (2017). Why don't European girls like science or technology?, https://news.microsoft.com/europe/features/dont-european-girls-like-science-technology/, Março. 